\title{
Antioxidant activity of tuberosin isolated from Pueraria tuberose Linn
}

\author{
Nidhi Pandey, Yamini B Tripathi*
}

\begin{abstract}
Antioxidant activity of Pueraria tuberose DC, (PT) Leguminosae (Fabaceae) has already been reported by us and here an active compound has been isolated and its action on expression of iNOS protein has been explored by using LPS induced changes in attached rat peritoneal macrophage cell culture. The pure compound was isolated by column chromatography and its structure was characterized by spectral studies, which was identified as tuberosin (5 hydroxy $3,4,7,3^{\prime}, 4^{\prime}$ pentamethoxy flavone). Its antioxidant capacity was determined and compared with alcoholic extract as $E_{50}$ value for scavenging potential towards pre-generated monocation ABTS* radical, superoxide radicals, hydroxyl radicals, metal chelation property and on lipid peroxidation. Further, rat peritoneal macrophages were isolated, cultured and the attached macrophages were exposed to lipopolysaccharide (LPS) with different concentrations of tuberosin (pretreatment for $30 \mathrm{~min}$ ). After $17 \mathrm{~h}$ the released $\mathrm{NO}$ content, in culture supernatant, was indirectly estimated as accumulated nitrite by Griess reagent. To understand the mechanism of action, the extent of expression of inducible nitric oxide synthase genes, the iNOS protein was assessed in macrophage lysate by using its antibody on western blot analysis. Tuberosin significantly scavenged all the species of FRs, described above and it also inhibited the LPS induced release of NO and amount of iNOS protein in macrophages. All the changes were significant and concentration dependent. Thus it could be suggested that tuberosin, is one of the active principles of Pueraria tuberose, which directly scavenges various species of Free radicals (FRs) and also inhibits LPS induced inflammatory changes in macrophages.
\end{abstract}

\section{Background}

In recent years, phyto-medicine is in great demand as food supplement for age related chronic diseases, because of their multi-targeted action and lesser side effects [1] In fact, these diseases are associated with generation of excessive free radical (FR) [2] and associated inflammation [3] and these herbal products are rich in polyphenols, specially flavones and tannins. Therefore, search for potent antioxidants with anti-inflammatory potential has always been in demand. In various countries, these herbs are used as a component of their alternative system of medicine [4] and in Ayurveda, an Indian system of medicine, medicinal plants are well documented for their therapeutic claims, with records of long clinical use, for prevention and management of several metabolic disorders [5].

Pueraria tuberosa Linn (PT), Leguminosae (Fabaceae), known as Bidaarikand [6] is an extensive perennial

\footnotetext{
* Correspondence: yaminiok@yahoo.com

Department of Medicinal Chemistry, Institute of Medical Science, Banaras Hindu University, Varanasi-221005, India
}

climber, with palmately arranged leaves, blue colored flowers and half inches thick bark [7], growing throughout tropical parts of India, mostly in moist regions, monsoon forests and coastal tracts. Its tuberous root, which is brown in color and slightly curved, is in clinical use for rejuvenation therapy. Its microscopic picture reveals the presence of prismatic calcium crystals and tanniniferous cells. It's major chemical constituents include flavones [C-glycoside (5,7,3',5'-tetrahydroxy-4'-methoxyflavone-3'O- $\alpha$-Lrhamnopyranosyl $1 \rightarrow 3-O-\beta$-D-galactopyranoside)], Isoflavones (Puerarone), Coumstan (Tuberostan, Puerarostan) [8], Epoxychalcanol [Puetuberosanol], (3'hydroxy-4'-phenoxy- $\alpha, \beta$-epoxychalcan- $\alpha$ 'ol)] [9], Pterocarpanoids [Hydroxytuberosin, Anhydroxytuberosin (3-O-methylanhydrotuberosin)] [10], and Tuberosin [11]. The powder of PT root-tubers are in clinical use as antiaging and also as tonic, aphrodisiac, demulcent, lactagogue, purgative, cholagogue and also in scorpion sting. Besides, it is also useful in emaciation of children, debility and poor digestion [6,7]. Other investigators have reported it for skin care, as anti-fertility [12]. One of its 
phytochemical, purerin, has been associated with antidiabetic property [13].

The presence of free transition metals in the biological system leads to excessive generation of free radicals [14]. However when the natural antioxidant enzymes are not sufficient to scavenge these active FRs, then their unusual longer persistence in the cell, causes peroxidation of cellular lipids and proteins, which results to damage of cell-organelles. Further these oxidized macromolecules behave as foreign proteins and affect the immune system. They may activate the inflammatory cascade, resulting in initiation of various degenerative diseases and autoimmune disorders [15]. Therefore, these antioxidants have variety of other biological responses, because of their indirect influence on inflammatory and immunity pathway. To name a few, these includes eugenol, gallic acid and quercetin [16-19].

As we have already reported the antioxidant property of PT tuber extract [20], so here its active principle has been isolated and the role of inflammation has been explored. Since alcoholic fraction of PT tuber had shown most potent FR scavenging potential, therefore it was subjected to column chromatography and the isolated compounds were tested for their antioxidant potential and one of its most active compounds was characterized by spectral analysis. Its property was compared with its mother extract in terms of their $\mathrm{EC}_{50}$. Further, its anti-inflammatory property was explored by monitoring its inhibitory effect on LPS (Lipopolysaccharide) induced expression of inducible nitric oxide synthase (iNOS) and release of nitric oxide (NO) in the culture supernatant, by attached rat peritoneal macrophages culture.

\section{Methods}

\section{Material}

2,2'-azinobis-3-ethyl benzothiazoline-6-sulfonic acid (ABTS*), Deoxyribose, were purchased from Sigma Aldrich Co. USA. Nitrobluetetrazolium (NBT), Riboflavin, L-methionine, thiobarbituric acid, Ethylenediamine tetra acetic acid (EDTA) were purchased from Hi-Media Ltd, ferric chloride anhydrous $\left(\mathrm{FeCl}_{3}\right)$ ascorbic acid, trichloro acetic acid, potassium persulfate Vitamin $\mathrm{C}$ were purchased from Merck Ltd. All the other reagents were of analytical grade.

\section{Isolation and characterization of Tuberosin}

The root-tubers of Pueraria tuberose were purchased from local market and its authenticity was rechecked on pharmacognostical parameters. Its voucher specimen was persevered in the dept. (No. YBT/MC/12/1-2007). The dried root-tuber -powder was successively extracted with hexane and then with ethanol in a soxhlet extractor. The solvent free alcoholic extract (yield-12-18\% w/w) was saved for column chromatography. $8 \mathrm{~g}$ of this extract was separated over silica gel column $(80 \times 4 \mathrm{~cm})$ and eluted with organic solvent with increasing polarity. The ethyl acetate fraction was subjected to re-chromatography on a smaller silica gel column $(30 \times 1.5 \mathrm{~cm})$ by using benzene: ethyl acetate (7:3) as elution solvent. The isolated compound was re-crystallized from benzene, which furnished white crystals, m.p. $271-272^{\circ} \mathrm{C}$. Its purity was confirmed by thin layer chromatography on silica gel $\mathrm{G}$ plate, where it showed single spot of Rf value 0.45 with solvent, Benzene: Chloroform (6:4). The spectral data of the isolated compound (UV, IR and NMR) were compared with the data of other compounds, isolated from PT extract and reported in the literature [11]. Based on similarity, this biologically active isolated compound was identified as 5 hydroxy 3,4,7,3',4' pentamethoxy flavone (Tuberosin).

\section{Assay of antioxidant property a. ABTS* radical scavenging activity}

ABTS* radical scavenging activity of tuberosin was determined according to Re et al. [21], where ABTS* radicals were pre-generated by mixing solutions of ABTS $^{*}(14 \mathrm{mM})$ and potassium persulphate $(4.9 \mathrm{mM})$. After mixing different concentrations of the test compound with the ABTS* solution, the reduction in degree of absorbance was recorded at $734 \mathrm{~nm}$.

\section{b. Lipid peroxidation assay}

Lipid Peroxidation assay was carried out by modified method to measure thiobarbituric acid-reactive substances (TBARS) [22], where $\mathrm{FeSO}_{4}$ was used to induce lipid peroxidation in egg yolk homogenates [23]. The pink colour, developed after heating the reaction mixture in water bath for $1 \mathrm{~h}$, was read at $532 \mathrm{~nm}$.

\section{c. Superoxide radical scavenging property}

Superoxide radical scavenging property was assessed by monitoring the capacity of test compounds to scavenge instantly generated superoxides, through riboflavin mediated photosensitive reaction. The added NBT solution reacted with superoxide radicals and rate of formation of its coloured product was monitored at $560 \mathrm{~nm}$ [24].

\section{d. Hydroxyl radical scavenging property}

Similarly, hydroxyl radical scavenging potential was measured by Non Site-specific hydroxyl radicalmediated 2-deoxy-D-ribose degradation. Here, the reaction was carried out in presence of $\mathrm{FeCl}_{3}$ and EDTA. Here, its complex reacted with $\mathrm{H}_{2} \mathrm{O}_{2}$ in presence of ascorbic acid to produce $\mathrm{OH}$ radicals, which degraded the deoxyribose to a coloured end product, which was monitored at $532 \mathrm{~nm}$. Finally to assess the metal chelating property of the test material, the Site-specific hydroxyl radical-mediated 2-deoxy-D-ribose degradation was monitored, where the above reaction was carried out in absence of EDTA. The difference in the readings of the 
above 2 reactions were considered as degree of metal chelation [25].

\section{Effect on NO production}

Inbred male rats of Charls foster (CF) strain of matched age and weight were purchased from the central animal house of Institute of Medical Sciences and acclimatized in our laboratory conditions for 7 days. On the experimental day, the rats were anaesthetized by injecting ketamine and $10 \mathrm{ml}$ of sterile ice-cold phosphate buffer saline, devoid of calcium and magnesium ions was injected in to the peritoneal cavity to each rat, through a syringe [26]. The abdomen was squeezed for $5 \mathrm{~min}$, and then the peritoneal fluid was aspirated out. It was centrifuged and the cell pellet was washed 2 times with serum free RPMI-1640 media to harvest the macrophages. This cell preparation was finally suspended in a known volume of complete RPMI-1640 media supplemented with $5 \%$ fetal calf serum (FCS). The isolated macrophages were counted by trypan blue exclusion method in haemocytometer and appropriately diluted to have $1 \times 10^{4}$ cells in $200 \mu \mathrm{l}$, which was taken in each cavity of 96 well culture plate. The plate was incubated for $2 \mathrm{hr}$ at $37^{\circ} \mathrm{C}$ in $5 \% \mathrm{CO}_{2}$ atmosphere to attach the living macrophages $[27,28]$ and then culture supernatant was replaced with fresh complete media. The attached macrophages were used for various experiments as described in respective tables. All tests were carried out in triplicate. In one set only drug vehicle (0.1\% DMSO) was added, in another set, quercetin was added as positive control and in test wells, different concentrations of tuberosin were added. After pre-incubation for $30 \mathrm{~min}$, LPS (20 ng/ml) was added to each well, mixed and incubated overnight for 17 hours to induce nitric oxide (NO) production. Next day, accumulated nitrite in the culture supernatant was monitored by using Griess reagent [29] ( $1 \%$ sulfanilamide/ $0.1 \%$ naphthalene diamine dihydrochloride $\left.2.5 \% \mathrm{H}_{3} \mathrm{PO}_{4}\right)$. Absorbance was read at $550 \mathrm{~nm}$ in an ELISA plate reader (Multiscan). It is an indirect method to measure the accumulated nitrite in the culture supernatant, which reflects the concentration of released nitric oxide. The $\mathrm{EC}_{50}$ value of isolated compound (concentration of sample required to inhibit 50\% response of LPS for NO production) for each parameter were determined by statistical formula, given below in the method section.

\section{Effect on iNOS expression by Western blot Analysis}

After removing the culture supernatant for nitrite estimation, the attached macrophages were washed with PBS and then lysed by adding $200 \mu \mathrm{l}$ lysis buffer ( 20 $\mathrm{mM}$ Tris-Buffer $(\mathrm{pH}=7.4)$, containing 0.25 sucrose, EDTA $(1 \mathrm{mM})$, PMSF $\left(100 \mu \mathrm{g} \mathrm{ml}^{-1}\right)$, aprotinin $(10 \mu \mathrm{g}$ $\left.\mathrm{ml}^{-1}\right)$, leupeptin $\left(10 \mu \mathrm{g} \mathrm{ml}^{-1}\right)$. The protein of this cell lysate was estimated by Bradford method [30] and its 20 $\mu \mathrm{g}$ protein was run in each lane on $8 \%$ sodium dodecyl sulphate-polyacrylamide gel electrophoresis (SDS-PAGE) [31]. The separated protein bands were transferred to nitrocellulose membrane by electro-blotting, washed with TBS (Tris-buffered saline) containing $0.05 \%(\mathrm{v} / \mathrm{v})$ Tween 20 and blocked with 5\% (wt/vol) dried non-fat milk in TBS for 2 hrs. Finally, the blot was incubated with rabbit polyclonal anti-iNOS antibody (SC650, Santa Cruz Biotechnology, 1/1000 in TBS-Tween-20 buffer) at $4^{\circ} \mathrm{C}$ overnight and visualized by alkaline phosphataseconjugated anti-rabbit IgG as the secondary antibody. DAB (diamminobenzidine) was used as substrate [32]. The intensity of bands was analyzed by image analyzer2254. The equal loading of sample in each lane was confirmed by monitoring the expression of $\mathrm{B}$-actin.

\section{Statistics}

All data were expressed as means \pm SD. Pearson's correlation analysis (SPSS 7.5 for Windows, SPSS Inc.) was used to test for the significance of relationship between the concentration and percentage inhibition at a $p<0.05$ significance level. The $\mathrm{EC}_{50}$ of for different parameters were calculated by using the following formula

$$
\mathrm{Y}_{50}=\mathrm{A}+\mathrm{BX}
$$

Where, $\mathrm{A}=$ Mean of $\times-\mathrm{B}$ (predicted $\mathrm{Y}$ value $=, 50 \%)$

$$
B=\frac{\sum \mathrm{X} . \mathrm{Y}-\left(\sum \mathrm{X}\right)\left(\sum \mathrm{Y}\right) / \mathrm{N}}{\sum \mathrm{Y}^{2}-\left(\sum \mathrm{Y} / \mathrm{N}\right)^{2}}
$$

$\mathrm{X}=$ independent variable (Concentration of Drug)

$\mathrm{Y}=$ dependent variable (\% inhibition)

\section{Results}

\section{(1) Characterization of Tuberosin}

The spectral data of the isolated compound for UV, IR, ${ }^{1} \mathrm{H}-\mathrm{NMR}$, and ${ }^{13} \mathrm{C}$ NMR (Table 1 ) were compared with the data available in the literature and based on the similarity, the isolated compound was identified as was tuberosin (figure 1).

\section{(2). ABTS* assay}

Tuberosin scavenged the pre-generated ABTS* radicals in concentration-dependent manner, with $\mathrm{EC}_{50}$ values as $70 \mathrm{ng} / \mathrm{ml}$, which was lower as compared to its mother extract (alcoholic fraction of PT- $320 \mu \mathrm{mug} / \mathrm{ml}$ ). The difference was in the range of 44.71 fold (Table 2).

\section{(3). Superoxide scavenging assay}

Tuberosin also scavenged the instantly generated superoxide radicals in a concentration-dependent manner with $\mathrm{EC}_{50}$ value at $156 \mu \mathrm{mug} / \mathrm{ml}$ (Table 2), which was 
Table 1 Analytical data of isolated compound (Tuberosin; 5hydroxy 3,6,7,3'4' pentamethoxy flavone)

\begin{tabular}{|c|c|}
\hline Melting point & $271-72^{\circ} \mathrm{C}$ \\
\hline TLC pattern & $\begin{array}{l}\text { Solvent system: benzene:ethyl acetate }(7: 3) \\
\text { RF value: } 0.45\end{array}$ \\
\hline$\overline{\mathrm{UV}(\mathrm{MeOH})}$ & $\begin{array}{l}(\log \varepsilon): 255(4.26), \\
274(4.18) \text { and } \\
346 \mathrm{~nm}(4.21)\end{array}$ \\
\hline$\overline{\mathrm{IR}(\mathrm{KBr}) \mathrm{cm}^{-1}}$ & 3480,1664 and 1559 \\
\hline${ }^{1} \mathrm{H} \mathrm{NMR}\left(\mathrm{CDCl}_{3}\right)$ & $\begin{array}{l}\delta 12.62(1 \mathrm{H}, \mathrm{s}, \mathrm{O}-\mathrm{H}), 7.75\left(2 \mathrm{H}, \mathrm{m}, 2^{\prime}-\mathrm{H} \text { and } 6^{\prime}-\mathrm{H}\right), 7.01\left(1 \mathrm{H}, \mathrm{d}, \mathrm{J}=9.0 \mathrm{~Hz}, 5^{\prime}-\mathrm{H}\right), 6.51(1 \mathrm{H}, \mathrm{s}, 8-\mathrm{H}), 3.98(9 \mathrm{H}, \mathrm{s}, 3 \times \\
\left.\mathrm{OCH}_{3}\right), 3.93(3 \mathrm{H}, \mathrm{s}, \mathrm{OCH}) \text { and } 3.87\left(3 \mathrm{H}, \mathrm{s}, \mathrm{OCH} \mathrm{CH}_{3}\right) .\end{array}$ \\
\hline${ }^{13} \mathrm{CNMR}$ & $\begin{array}{l}\delta 158.7(\mathrm{C}-2), 132.4(\mathrm{C}-3), 178.8(\mathrm{C}-4), 155.7(\mathrm{C}-5), 138.8(\mathrm{C}-6), 152.7(\mathrm{C}-7), 90.3(\mathrm{C}-8), 151.5(\mathrm{C}-9), 106.6(\mathrm{C}-10), 122.9\left(\mathrm{C}-1^{\prime}\right), \\
111.7\left(\mathrm{C}-2^{\prime}\right), 148.9\left(\mathrm{C}-3^{\prime}\right), 152.2\left(\mathrm{C}-4^{\prime}\right), 111.6\left(\mathrm{C}-5^{\prime}\right), 122.1\left(\mathrm{C}-6^{\prime}\right), 60.7\left(6-\mathrm{OCH}_{3}\right), 56.1\left(7-\mathrm{OCH}_{3}\right), 60.1\left(3-\mathrm{OCH}_{3}\right), 56.2\left(3^{\prime}-\mathrm{OCH}_{3}\right) \text { and } \\
55.9\left(4^{\prime}-\mathrm{OCH}_{3}\right) .\end{array}$ \\
\hline
\end{tabular}

1.5 times lower than it's alcoholic mother extract (240 $\mu \mathrm{mug} / \mathrm{ml})$.

\section{(4). Lipid Peroxidation Assay}

There was significant and concentration-dependent inhibition by tuberosin on $\mathrm{FeSO}_{4}$ induced lipid peroxidation (Table 3). Tuberosin had 7.95 fold lower $\mathrm{EC}_{50}$ value (98 $\mu \mathrm{mug} / \mathrm{ml})$ as compared to the alcoholic extract of PT $(780 \mu \mathrm{mug} / \mathrm{ml})$.

\section{(5). Non-site specific Hydroxyl radical scavenging assay (With EDTA)}

Tuberosin was found to be the more potent hydroxyl radical scavenger with $\mathrm{EC}_{50}$ values of $(32 \mu \mathrm{mug} / \mathrm{ml})$, which was 9.6 time lower than it's alcoholic fraction (EC E0 $310 \mu \mathrm{mug} / \mathrm{ml})$ (Table 4).

\section{(6) Site specific Hydroxyl radical scavenging assay (Without EDTA)}

Further in the case of Site specific Hydroxyl radical scavenging assay (without EDTA), $\mathrm{EC}_{50}$ values of tuberosin was at $28 \mu \mathrm{mug} / \mathrm{ml}$, which was lower than the value obtained in case of non site specific reaction (described above), suggesting its additional role as metal chelation (Table 4).

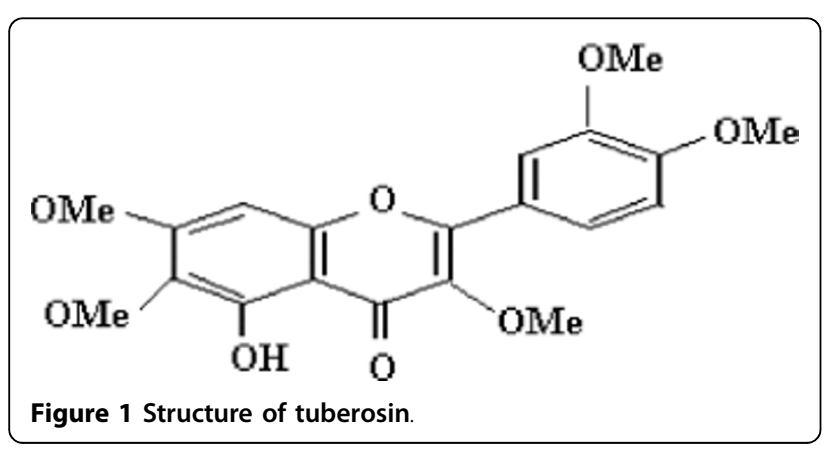

(7) Effect of tuberosin on LPS induced NO production and iNOS-protein expression in macrophages

Tuberosin significantly inhibited LPS induced release of nitric oxide (NO) by macrophages in concentrationdependent manner (Table 5). It also inhibited the accumulation of iNOS proteins in the attached macrophages (Figure 2).

\section{Discussion}

Various pure isolated phytochemicals or plant extracts having natural cocktail of various poly-phenolics, have shown antioxidant and anti-inflammatory property $[33,34]$. They are also in use for the management of age related chronic diseases such as diabetic complications [35], atherosclerosis [36] and inflammation [37], as food supplement or as add-on therapy with conventional medicine.

The powder of PT root-tubers are already in clinical use by Ayurvedic physicians of Indian system of medicine [6], but neither its mechanism of action nor the active principle for its antioxidant and anti-inflammatory property has been explored so far. Interestingly, our data has helped in characterizing the isolated compound as tuberosin, which has already been reported [11], but no biological activity related to LPS induced changes, has been available in the literature.

Tuberosin has exhibited direct FR trapping capacity in a chemical reaction system, however, variability in its potency towards various free radical species, could be because of the difference in the electron potential of these free radical species [38]. Further, the Fe induced lipid peroxidation in presence of ascorbic acid, is an example non-enzymatic process ( $\mathrm{Fe}^{++} /$ascorbic acid), therefore, the anti-lipid-peroxidative property of tuberosin, described above, indicates its total antioxidant capacity. As it has also shown metal chelation property along with direct FR trapping property, therefore the net response of inhibition towards lipid peroxidation could be a combined effect of these 2 responses. 
Table 2 Effect of tuberosin on pre-generated ABTS* radical and superoxide radical scavenging property

\begin{tabular}{lll}
\hline $\begin{array}{l}\text { Concentration of } \\
\text { tuberosin }(\mu \mathrm{M})\end{array}$ & $\begin{array}{l}\text { \% decrease in absorbance at } \mathbf{7 3 4} \mathbf{n m} \text { (mean } \pm \text { S.D.) for } \\
\text { ABTS* radical scavenging }\end{array}$ & $\begin{array}{l}\text { \% decrease in absorbance at 560 } \mathrm{nm}(\text { mean } \pm \text { S.D.) for } \\
\text { SO radical scavenging }\end{array}$ \\
\hline 50 & $8.42 \pm 0.99^{*}$ & $5.78 \pm 0.46^{* *}$ \\
\hline 125 & $24.09 \pm 0.33^{*}$ & $18.98 \pm 0.76^{* *}$ \\
\hline 200 & $45.16 \pm 0.89^{*}$ & $27.89 \pm 0.55^{* *}$ \\
\hline 250 & $60.00 \pm 1.05^{*}$ & $54.78 \pm 0.87^{* *}$ \\
\hline 375 & $77.25 \pm 1.06^{*}$ & $67.11 \pm 0.77^{* *}$ \\
\hline 500 & $93.08 \pm 0.63^{*}$ & $83.44 \pm 0.63^{* *}$ \\
\hline$E C_{50}$ & $97.24 \pm 0.89^{*}$ & $97.24 \pm 1.22^{* *}$ \\
\hline & $198.67 \mu \mathrm{muM}$ & $205.11 \mu \mathrm{muM}$ \\
\hline
\end{tabular}

$\mathrm{n}=3$, Level of significance: $\mathrm{p}^{*}<0.1$ and $\mathrm{p}^{* *}<0.001$

Table 3 Inhibition of lipid peroxidation induced by $\mathrm{FeSO}_{4}$ using egg yolk homogenates

\begin{tabular}{lll}
\hline Concentration of tuberosin $(\mathbf{m M})$ & $\begin{array}{l}\text { Absorbance at } \mathbf{5 3 2} \mathbf{n m} \\
(\text { mean } \pm \text { SD) }\end{array}$ & $\begin{array}{l}\text { \% decrease in absorbance } \\
\text { (mean } \pm \text { SD) }\end{array}$ \\
\hline Blank & 0.380 & - \\
\hline control & 0.355 & - \\
\hline 12 & $0.320 \pm .021^{*}$ & $7.08 \pm 1.30$ \\
\hline 18 & $0.283 \pm .020^{*}$ & $17.89 \pm 1.00$ \\
\hline 25 & $0.248 \pm .018^{* *}$ & $27.98 \pm 1.42$ \\
\hline 30 & $0.198 \pm .015^{* *}$ & $42.74 \pm 0.96$ \\
\hline 40 & $0.131 \pm .010^{* *}$ & $62.05 \pm 1.50$ \\
\hline 45 & $0.073 \pm .002^{* *}$ & $78.76 \pm 1.16$ \\
\hline 50 & $0.049 \pm .001^{* *}$ & $85.83 \pm 1.30$ \\
\hline
\end{tabular}

$\mathrm{n}=3 \mathrm{EC}_{50}$ of tuberosin- $49.22 \mathrm{mM}, \mathrm{EC}_{50}$ for quercetin- $0.60 \mu \mathrm{muM} \mathrm{M}^{\varrho}$

Level of significance: $\mathrm{p}^{*}<0.1$ and $\mathrm{p}^{* *}<0.001$. ${ }^{\circledR}$ Reference 18

Table 4 Effect of tuberosin in the deoxyribose assay in the presence of EDTA (non-site specific) to assess the Hydroxyl radical scavenging activity and absence of EDTA (site specific) to assess metal chelation property

\begin{tabular}{|c|c|c|c|c|}
\hline \multirow[t]{2}{*}{ Concentration of tuberosin (mM) } & \multicolumn{2}{|c|}{ Absorbance at $532 \mathrm{~nm}$ (mean \pm S.D) } & \multicolumn{2}{|c|}{$\begin{array}{l}\% \text { decrease in absorbance } \\
\text { (mean } \pm \text { SD) }\end{array}$} \\
\hline & (Non site specific) & (Site specific) & (Non site specific) & (Site specific) \\
\hline Normal & $0.310 \pm .018$ & $0.515 \pm .028$ & - & - \\
\hline Blank & $0.288 \pm .017$ & $0.485 \pm .022$ & - & - \\
\hline 0.25 & $0.280 \pm 0.014^{*}$ & $0.400 \pm .024^{*}$ & $2.60 \pm 0.94$ & $17.54 \pm 1.25$ \\
\hline 0.50 & $0.256 \pm .015^{*}$ & $0.356 \pm .021^{* *}$ & $11.22 \pm 0.97$ & $26.54 \pm 1.15$ \\
\hline 0.75 & $0.235 \pm .013^{* *}$ & $0.311 \pm .020^{* *}$ & $18.35 \pm 0.88$ & $35.82 \pm 0.91$ \\
\hline 1.00 & $0.199 \pm .012^{* *}$ & $0.271 \pm .018^{* *}$ & $30.73 \pm 1.08$ & $44.08 \pm 0.96$ \\
\hline 1.25 & $0.156 \pm .011^{* *}$ & $0.190 \pm .011^{* *}$ & $45.94 \pm 0.94$ & $60.80 \pm 0.94$ \\
\hline 1.80 & $0.125 \pm .010^{* *}$ & $0.119 \pm .008^{* *}$ & $56.72 \pm 1.14$ & $75.51 \pm 0.99$ \\
\hline 2.50 & $0.092 \pm .007^{* *}$ & $0.01 \pm .001^{* *}$ & $67.94 \pm 0.67$ & $98.04 \pm 0.62$ \\
\hline
\end{tabular}

$\mathrm{n}=3$; $\mathrm{EC}_{50}$ of tuberosin: Non site specific assay $=1.14 \mathrm{mM}$ and site specific assay $=0.918 \mathrm{mM} ; \mathrm{EC}_{50}(\mu \mathrm{muM})$ for quercetin - Non site specific assay 0.80 and site specific assay- 0.50 ; Level of significance: $p^{*}<0.1$ and $p^{* *}<0.001$. 
Table 5 Effect of tuberosin on LPS induced NO production and iNOS expression by attached rat peritoneal macrophages.

\begin{tabular}{|c|c|c|}
\hline Concentration of tuberosin $(\mathrm{ng} / \mathrm{ml})$ & NO production ( $\mu \mathrm{g} / 10^{4}$ cells) & Pixel value of iNOS bands in western blot \\
\hline Normal Cells & $10.11 \pm 1.043$ & - \\
\hline Only LPS (20 ng/ml) & $39.89 \pm 1.983$ & 16023 \\
\hline LPS(20 ng/ml)+Tuberosin(ng/ml) & & - \\
\hline 100 & $38.09 \pm 1.933$ & 15878 \\
\hline 200 & $36.09 \pm 1.862^{* *}$ & - \\
\hline 300 & $27.02 \pm 1.698^{* *}$ & 10678 \\
\hline 400 & $21.16 \pm 1.829^{*}$ & - \\
\hline 500 & $13.04 \pm 1.904^{*}$ & - \\
\hline 600 & $10.09 \pm 1.898^{*}$ & 5082 \\
\hline$\underline{\text { LPS + Quercetin }(50 \text { ng/ml) }}$ & $9.98 \pm 1.041$ & 4223 \\
\hline $\mathrm{EC}_{50}$ of tuberosin & $399.68 \mathrm{ng} / \mathrm{ml}$ & - \\
\hline $\mathrm{EC}_{50}$ of quercetin & $190 \mathrm{ng} / \mathrm{ml}$ & - \\
\hline
\end{tabular}

Values were significant $\left(p^{*}<0.1, p^{* *}<0.001\right)$ when compared with experimental control.

Tuberosine has shown lower $\mathrm{EC}_{50}$ value on all tested parameters than its mother alcoholic extract, which suggests its higher potency, and therefore it could be considered as its active principle. However, it has been found to be significantly less potent than quercetin, which could be because of structural difference in these two compounds. It has been documented earlier that number and position of hydroxyl groups in the flavones ring, regulates

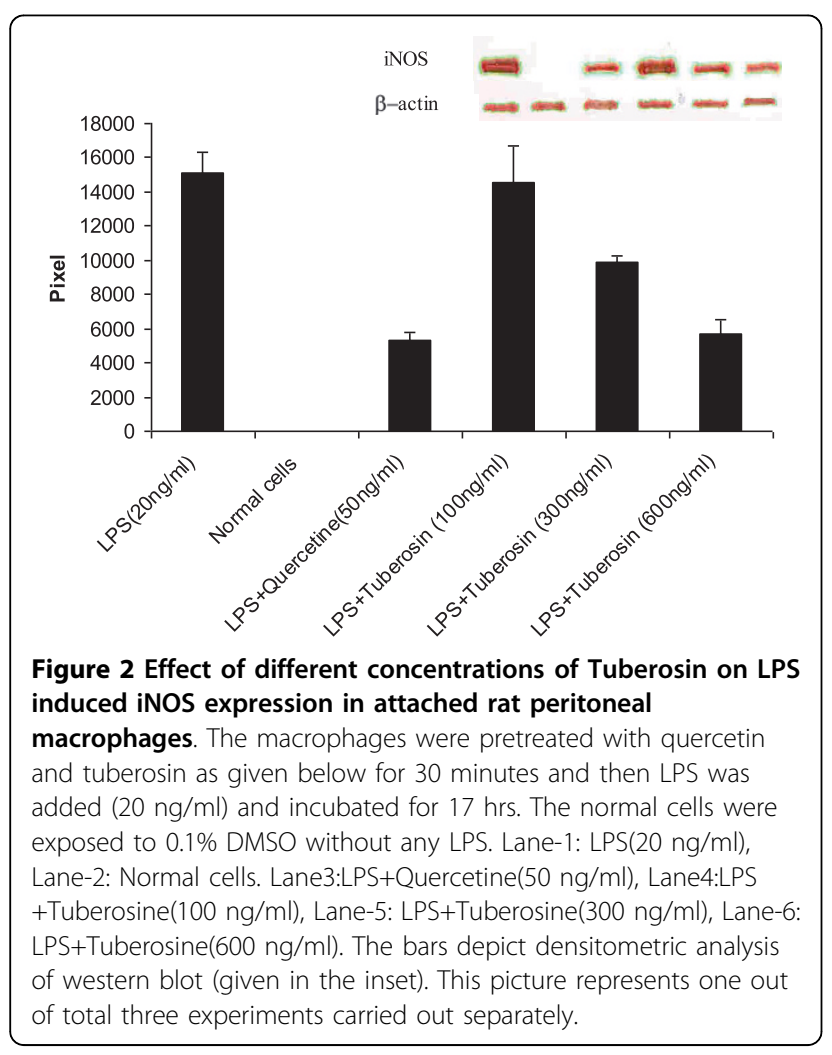

its antioxidant potential and the presence of 3-OH makes the compound more potent than that of $5-\mathrm{OH}$ group [39]. From the structural comparison of these 2 compounds, it is clear that tuberosine has $5-\mathrm{OH}$ group, where as quercetin has $3-\mathrm{OH}$ group. Thus, the higher potency of quercetin over tuberosin could be explained.

Measurement of inhibitory property of a test compound against LPS induced NO release is one of the standard models to explore anti-inflammatory potential of any test drug. LPS is known to induce iNOS through activation of NF-kB and this process involves free radicals (FR) in its early steps, just after interacting with its Toll-like receptor (TLR) $[40,41]$. Therefore, free radical scavengers have been reported earlier to inhibit this process and our data has also shown concentration-dependent inhibition of LPS induced NO release. This trapping capacity of tuberosin, for variety of free radical species and also for metal chelation property has been found in our in vitro testing on a chemical test model. Thus, it could be suggested that tuberosin might be acting on the initial steps of the signaling cascade of LPS induced NO production, but it is still not clear, whether it is directly inhibiting the activity of iNOS enzyme or it is suppressing the synthesis of this enzyme.

To target this question, we explored the effect of tuberosin on iNOS protein in macrophages, when exposed to LPS. Interestingly, our data show that tuberosin significantly inhibited the iNOS protein in western blot analysis. The results suggested that tuberosin is inhibiting the expression of iNOS genes, as amount of iNOS proteins was significantly lower in tuberosin pretreated cells in concentration dependent manner.

\section{Conclusion}

From the above experimental results, it could be suggested that tuberosin is one of the active principles of 
Pueraria tuberose for its claimed antioxidant property. The tuberosine has direct scavenging potential for variety of free radicals with preference to ABTS* radicals followed by hydroxyl radicals and then superoxide radicals. It has additional metal chelation property. Tuberosin has potential to inhibit LPS induced NO production in concentration-dependent manner, which is due to inhibition in the expression of iNOS proteins.

\section{Acknowledgements}

Authors are thankful to Banaras Hindu University, for extending the infrastructure and for fellowship of Ms Nidhi Pandey. We acknowledge the help of Prof SK Upadhyay for statistical analysis, Prof SK Trigun for western blot analysis. The financial help from an ongoing CSIR project is also acknowledged for purchase of chemicals and glass wares.

\section{Authors' contributions}

NP carried out the experimental works. YBT conceived of the study, and participated in its design, discussion of results, over all coordination and wrote the manuscript. All authors read and approved the final manuscript.

\section{Competing interests}

The authors declare that they have no competing interests.

Received: 30 June 2009 Accepted: 14 September 2010

Published: 14 September 2010

\section{References}

1. Tripathi YB, Tripathi P, Arjmandi BH: Nutraceuticals and cancer management. Frontiers in Bioscience 2005, 10:1607-1618.

2. Winrow VR, Winyard PG, Morris CJ, Blake DR: Free radicals in inflammation: second messengers and mediators of tissue destruction. British Medical Bulletin 1993, 49:506-522.

3. Wilson JD, Robinson AJ, Kinghorn SA, Hicks DA: Implications of inflammatory changes on cervical cytology. BMJ 1990, 10(Suppl 6725):638-640

4. Gacche RN, Dholen A: Antioxidant and possible anti-inflammatory potential of selected medicinal plants prescribed in the Indian traditional system of medicine. Pharmaceutical biology 2006, 44:389-395.

5. Tripathi YB, Tripathi P, Korlagunta K, Chai SC, Smith BJ, Arjmandi BH: Role of Sandhika: A Polyherbal Formulation on MC3T3-E1 Osteoblast-like Cells. Inflammation 2008, 31(suppl 1):1-8.

6. Chopra RN, Nayar SL, Chopra IC: Glossary of Indian Medicinal Plants. CISR New Delhi 1956, 256

7. Pandey GS, Chunekar KC, Vidari K, (Eds): Bhav Prakash Nighantu. ChaukambhaVidya Bhavan, Varanasi 1998, 1:388-89.

8. Ramakrishna KV, Khan RA, Kapil RS: A new isoflavone and Coumestan from Pueraria tuberosa. Indian Journal of Chemistry, Section B: Organic Chemistry including Medicinal Chemistry Central Drug Research Institute Lucknow, India 1998, 27(3):285.

9. Pawan K, Khan RA, Agrawal, Kapil RS: Puetuberosanol an epoxychalcanol from Pueraria tuberosa. Phytochemistry(Oxford) 1996, 42(1):243-244.

10. Prasad AVK, Kapil RS, Polpi SP: Structure of Pterocarponoids anhydrotuberosin 3-O methylanhydrotuberosin and tuberostan from Pueraria tuberosa. Indian journal of chemistry, section B, organic chemistry including medicinal chemistry 1985, 24(3):236-239.

11. Joshi BN, Kamat VN, Govindachari TR: Structure of tuberosin, a new pterocarpan from Pueraria tuberosa. India Indian Journal of Chemistry Ciba Research Centre Bombay 1972, 10(11):1112-3.

12. Gupta RS, Sharma R, Choudhary R, Bhatnagar AK, Joshi YC: Antifertility effect of Pueraria tuberosa root extract on male rats. Pharmaceutical Biology 2004, 42(8):603-609.

13. Xiong $F L$, Sun $X H$, Gan L, Yang XL, Xu HB: Puerarin protects rat pancreatic islets from damage by hydrogen peroxide. Eur J Pharmacol 2006, 529(1-3):1-7.
14. Ong WY, Halliwell B: Iron atheroscelosis, and neurodegeneration: a key role for cholesterol in promoting iron- dependent oxidative damage? Ann N Y Acad Sci 2004, 1012:51-64, (Review).

15. Halliwell B, Gutteridge JM, Blake D: Metal ions and oxygen radical reactions in human inflammatory joint disease. Philos Trans $R$ Soc Lond $B$ Biol Sci 1985, 311(1152):659-71.

16. Kroes BH, vanden Berg AJ, Quarles van Ufford HC, van Dijk, Labadie RP: Anti-inflammatory activity of gallic acid. Planta Med 1992, 58(6):499-504.

17. Victoria García-Mediavilla Irene Crespo, Collado SPilar, Esteller Alejandro, Sánchez-Campos Sonia, Tuñón JMaría, González-Gallego Javier: The antiinflammatory flavones quercetin and kaempferol cause inhibition of inducible nitric oxide synthase, cyclooxygenase- 2 and reactive C-protein, and down-regulation of the nuclear factor kappaB pathway in Chang Liver cells. European Journal of Pharmacology 2007, 557(2-3):221-229.

18. Verdrengh $M$, Jonsson IM, Holmdahl R, Tarkowski A: Genistein as an antiinflammatory agent. Inflamm Res 2003, 52(8):341-6.

19. Wang Y, Ho CT: Metabolism of Flavonoids Forum. Nutr 2009, , 61: 64-74.

20. Pandey Nidhi, Chaurasia JK, Tiwari OP, Tripathi Yamini B: Antioxidant properties of different fractions of tubers from Pueraria tuberosa Linn. Food Chemistry FOCHMS 2007, 105:219-222.

21. Re R, Pellegrini N, Proteggente A, Pannala A, Yang M, Rice-Evans C: Antioxidant acitivity applying an improved ABTS radical cation decolorizing assay. Free Radicals in Biology and Medicine 1999, , 26: 1231-1237.

22. Tiwari OP, Triapthi YB: Anti oxidant properties of different fractions of Vitex negundo. Food Chemistry 2007, 100:1170-1176.

23. Ohkowa H, Ohisi N, Yagi K: Assay for lipid peroxides in animals tissue by thiobarbituric acid reaction. Analytical Biochemistr 1979, 95:351-358.

24. Beauchamp C, Fridovich I: Superoxide dismutase: Improved assay and an assay applicable to acrylamide gels. Analytical Biochemistry 1971, 44:276-287.

25. Halliwell B, Gutteridge MC, Aruoma Ol: The deoxyribose method: a simple test-tube assay for determination of rate constants for reactions of hydroxyl radicals. Anal Biochem 1987, 165:215-219.

26. Satoh A, Shimosegawa T, Fujita M, Kimura K, Masamune A, Koizumi M, Toyota T: Inhibition of nuclear factor- B activation improves the survival of rats with taurocholate pancreatitis. GUT 1999, 44:253-258.

27. Machaiah JP, Vakil UK: Protein deficiency and age related alterations in rat peritoneal macrophage lipids. Journal of Biosciences 1989, 14:4.

28. Pandey RS, Singh BK, Tripathi Yamini B: Effect of gum rasin of Boswellia serrata L inhibits LPS induced NO production in rat Macrophages along with hypolipidemic property. Indian J of Expt Biol 2005, 43:509-516.

29. Griess JP: Bemerkungen zu der Abhandlung der HH: Wesely und Benedikt "Über einige Azoverbindungen". Ber Deutsch Chem Ges 1879, 12:426-428.

30. Bradford MM: A rapid and sensitive for the quantitation of microgram quantitites of protein utilizing the principle of protein-dye binding. Analytical Biochemistry 1976, 72:248-254.

31. Laemmli : Cleavage of structural proteins during the assembly of the head of bacteriophage T4. Nature 1970, 227(5259):680-685.

32. Towbin H, Staehelin T, Gordon J: Electrophoretic transfer of proteins from polyacrylamide gels to nitrocellulose sheets: procedure and some applications. Proc Natl Acad Sci USA 1979, 76(9):4350-4354.

33. Tripathi YB: BHUx: a patented poly herbal formulation to prevent hyperlipidemia and atherosclerosis. Recent Pat Inflamm Allergy Drug Discov 2009, 3(1):49-57.

34. Gayathri B, Manjula N, Vinaykumar KS, Lakshmi BS, Balakrishnan A: Pure compound from Boswellia serrata extract exhibits anti-inflammatory property in human PBMCs and mouse macrophages through inhibition of TNF $\alpha$, IL-1 $\beta$, NO and MAP kinases. International Immunopharmacology 2007, 7(4):473-482

35. Carl-David A, Unne S, Ole T, Elisabet A: Effects of inhibition of glycation and oxidative stress on the development of diabetic nephropathy in rats. Journal of diabetes and its complications 2002, 6(16):395-400.

36. Tripathi YB, Reddy MM, Pandey RS, Subhashini J, Tiwari OP, Singh BK, Reddanna P: Anti-inflammatory properties of BHUx, a polyherbal formulation to prevent atherosclerosis. Inflammopharmacology 2004, 12(2):131-52.

37. Chaurasia S, Tripathi P, Tripathi YB: Antioxidant and anti-inflammatory property of Sandhika: a compound herbal drug. Indian J Exp Biol 1995, 33(6):428-32. 
38. Pasha FA, Cho SJ, Beg Y, Tripathi YB: Quantum chemical QSAR study of flavones and their radical-scavengingactivity. Medicinal Chemistry Research 2007, 16(7-9):408-417.

39. Akir $\mathrm{E}$, Figen $\mathrm{E}$, Nevin $\mathrm{K}$ : Theoretical investigation of quercetin and its radicalisomers. Journal of Molecular Structure: THEOCHEM 2003, 631(13):141-146.

40. Ikeda K, Kubo S, Hirohashi K, Kinoshita H, Kaneda K, Kawada N, Sato EF, Inoue M: Mechanism that regulates nitric oxide production by lipopolysaccharide-stimulated rat Kupffer cells. Physiol Chem Phys Med NMR 1996, 28(4):239-53.

41. Je-Seong W, Yeong Bl, Singh AK, Singh I: Dual role of CAMP in iNOS expression in glial cells and macrophages is mediated by differential regulation of p38-MAPK/ATF-2 activation and iNOS stability. Free Radical Biology and Medicine 2004, 11(37):1834-1844.

doi:10.1186/1476-9255-7-47

Cite this article as: Pandey and Tripathi: Antioxidant activity of tuberosin isolated from Pueraria tuberose Linn. Journal of Inflammation 2010 7:47.

\section{Submit your next manuscript to BioMed Central} and take full advantage of:

- Convenient online submission

- Thorough peer review

- No space constraints or color figure charges

- Immediate publication on acceptance

- Inclusion in PubMed, CAS, Scopus and Google Scholar

- Research which is freely available for redistribution

Submit your manuscript at www.biomedcentral.com/submit
C Biomed Central 